\title{
The Synchronous Online Argumentation System User Interface with an Integrated Design Framework: Redesign and Evaluation
}

\author{
Ayu Nuswantari ${ }^{11}$, Ying-Tien $\mathbf{W u}^{2}$, Herman Dwi Surjono ${ }^{3}$ \\ ${ }^{1}$ Network Learning Technology, National Central University, Taiwan \\ \& Instructional Technology, Yogyakarta State University, Indonesia. \\ ${ }^{2}$ Network Learning Technology, National Central University, Taiwan. \\ ${ }_{3}^{3}$ Instructional Technology, Yogyakarta State University, Indonesia. \\ e-mail: ayunuswantari.2017@student.uny.ac.id, ytwu@cl.ncu.edu.tw, hermansurjono@uny.ac.id
}

\begin{abstract}
The Synchronous online argumentation system is highly needed to facilitate learning activity in this internet era. To gain deeper insights about this important issue, this study developed nine principles based on Cognitive Load, User Interface, and User Experience to redesign a system. With this framework, 48 (forty-eight) students of Chi-Ying High School had tested with two prototypes, and the second prototype used the nine principles. The systems were measured with Web-Based Learning Environment (WEBLEI) and System Usability Test (SUS). The result of WEBLEI measurement shows that the second prototype gives better result and shows higher user acceptance than the first prototype. The result of SUS measurement shows that the usability of the second prototype is better than on the first prototype with (4.43) SUS score difference. The result shows that the use of nine principles that applied to the second prototype does increase the usability and acceptance of the students.
\end{abstract}

Keywords: Synchronous Argumentation System; Design Principles; User Interface; Design Framework; Education

\section{Introduction}

According to previous research, synchronous communication has the potential to enhance student participation in online learning. "In recent years, Internet technologies have matured significantly. These advances, combined with the Internet's inherent characteristics of information availability through unrestricted time and space, means that it can now provide a uniform access medium for both asynchronous and synchronous learning. The technological advances include not only the rapid growth of information technologies but also the increasing availability of broadband Internet access, hence solving the problem of insufficient bandwidth. This technological growth has also resulted in the development of a variety of applications for online learning" (Chen et al., 2005). Online learning also become very popular among teachers and students around the world, so many researchers conducted experiments to develop systems to facilitate online learning, but not many of them provide the applicable principle to use on developing synchronous online learning system.

One of the advantages of synchronous online learning is, it will give immediate feedback to students, so they can immediately correct themselves and strengthen what they have learned (Hrastinski, 2007). This especially essential for activities such as group discussion, decision making, brainstorming, and analysis (Hotcomm, 2003). Synchronous online learning also could increase the level of motivation and will give the effect to an obligation to be present and participate in the activity, which in turn would increase student's involvement in learning activities, and would give better learning experiences. The other advantage of a synchronous online instruction is, it is flexible and distributed delivery that will allow learners and instructors to take part in a learning activity process from any geographic location. The activity through a synchronous online learning system communicates with one another; it could be one way from teacher to students like broadcast and could be communication among students like sharing ideas by argument. The characteristics of synchronous communication are that the

\footnotetext{
${ }^{1}$ Corresponding author.

Received 20 January 2020; Accepted 23 March 2020; Available online 31 March 2020 (c) 2020 JPI. All Rights Reserved
} 
conversations are conducted in real-time, and people are communicating together at the same time. The pedagogical assumption that motivates communicating in synchronously way is that participation is critical to the learning process (Leidner \& Jarvenpaa, 1995). Leidner and Jarvenpaa (1995) proved in their research that if all members of a class contributed in computer-mediated synchronous discussions and they communicated with each other rather than on a one-to-one basis with the teacher like in the traditional classroom, got a better result on developing their skill on problem-solving. A synchronous communication will be better to support personal participation because it involves the following key elements such as: (1) it would increase the psychological arousal, (2) it will increase the motivation, and (3) it will increase convergence on the meaning of the activity.

Synchronous Online collaborative argumentation learning system is a system that facilitates collaborative learning activity through the online real-time method. Students would experience learning activity through a system and would share their ideas and arguments to build new knowledge. The environment of this system is online, which means it can be accessed anywhere anytime with internet support. By synchronous online argument activity, students could share their ideas and build on new knowledge.

The argument learning activity is essential for students to enhance their skill on problemsolving, defend their opinion and reasoning, and it will make the students not only be able to share their ideas, but also understand why they stand their opinion, and they could also learn how to deal with other ideas. To design an excellent tool or system, the developer should develop a well-designed system according to reliable principles to attain the design purpose. A well-designed system is a system with a well-designed user interface and user experience.

The User Interface is the specific name for a visual appearance on a system. The User Interface is connecting the system to the user on using the system like a particular machine, device, computer program, or another complex tool. The User Interface is connected to the user by receives instructions from a terminal user to run a program or a system. In computer science and $\mathrm{HCl}$ (Human-Computer Interaction), The User Interface refers to the graphical, textual, and auditory information the program resents to the user and the control sequences, such as keystrokes with the touchscreen, movements of the computer mouse, and selections with the touchscreen which allows the user control the system (Sodiya, 2016).

User Interface design in this research is web-based system for an online system that resembles website chatting page with the focus on the user's experience and interaction. The purpose of User Interface design in this research is to make the user's interaction as simple and efficient as possible, and user-centered design in terms of accomplishing user goals on collaborative argumentation activity.

The User Experience is the activity and experience that the user will do on using and interact with a system. The User Experience is also connected to the user's behavior on using the system, based on the user ability, user-based knowledge, and user needs. The User Experience design is connected with The User Interface, because this will affect the usability aspect on the system, so the interface should support the user needs and consider about the user behavior on using the system based on their purpose on using the system. Many of the researchers tried to develop this kind of system, but not many of them provide an integrated framework to design the User Interface that could be implemented.

The aim of this study is to develop an integrated framework to be used in designing a system as a CSCL (Computer Supported Collaborative Learning) tool for argumentation learning by improving the User Interface and User Experience. In this research, we developed principles that adapted from Ten Usability Heuristics for User Interface Design by Jakob Nielsen (Nielsen, 1994) and The Eight Golden Rules of Interface Design by (Shneiderman et al., 2016) into nine principles; (1) The screen design is aesthetically pleasing, (2) The arrangement of options/menus is appropriate, (3) The screen layout is easy to understand, (4) Flexible and efficient to use (for novice and expert user), (5) Provide help option for the user, (6) Visibility of system status. Users should always know where they are and what is going on, (7) Consistency and standards. Use objects and phrases consistently, (8) Error prevention and make user able to delete or undo, and (9) Responsive. 
The instructional design model for developing the second prototype is the R2D2 model (Willis, 2009) because this instructional model is suitable to develop a product that based on constructivism learning activity such as an argumentation learning activity. In this study, the researcher used this R2D2 model to develop and enhanced the previous version/the first prototype to the second version. With this model, the designer and the observant are working together to develop the prototype as a design team. The design team works collaboratively in developing the second version of the synchronous argumentation system, and the user's opinion will help the developers to enhance the prototype. This model is suitable to provide the correlation about Synchronous Online, Cognitive Load, and R2D2 Model, User Interface and User Experience theory in terms of developing the framework because it provides the precise steps and purposes through all of the activity. The steps are practical and efficient to be applied to this kind of research that only has limited time to develop the product. R2D2 model has four principles (Botturi et al., 2006) they are: (1) Recursion (2) Reflection based on feedback and ideas, (3) Non-linearity and (4) Participatory design.

The evaluation in this study was done by measuring the usability aspect, "usability is a quality attribute that assesses how easy user interfaces are to use." (Nielsen, 2012) the word of usability is also referring to the methods for improving ease-of-use during the design process. Usability is also defined by five quality components, such as "Learnability" means how easy is it for the users to accomplish the tasks when they use the system, "Efficiency" means how quickly the uses can learn and perform to accomplish the tasks, "Memorability" means how easy the user could memorize the design function after not using it in some period of time, "Errors" means how many errors the user make while using the system and how easily they can figure out how to solve the problem, "Satisfaction" means how pleasant is it to use design, or user opinion about the design (Nielsen, 2012). To measure the result, we used WebBased Learning Environment (WEBLEI) adapted from (Chang, 2014) and The System Usability Test (SUS) adapted from Tullis and Stetson (Tullis \& Stetson, 2004) which containing all of the five usability aspects. To evaluate user acceptance and usability in using the systems.

In this paper, the objective is to identify the user acceptance and study the output and effect of implementing the nine design principles that we develop into a system with the aim of improving the usability and User Experience.

\section{Method}

The research participants were forty-eight $11^{\text {th }}$ grade English major students of Chi-Ying Senior High School located at Zhongyuan Road, No. 447, Zhongli District, Taoyuan City, 320, Taiwan. The experiment was conducted during the English lesson. The reason for choosing this school is because Chi-Ying Senior High School is one of the best school in Taoyuan, and reason choosing 11th grade is because students develop their critical and analytical thinking during this age.

The design process started from the first prototype, then through the Research and Development process. The researcher develops an enchanted version based on the principles; the enchanted version of the second prototype of the synchronous collaborative argumentation system named "The second prototype".

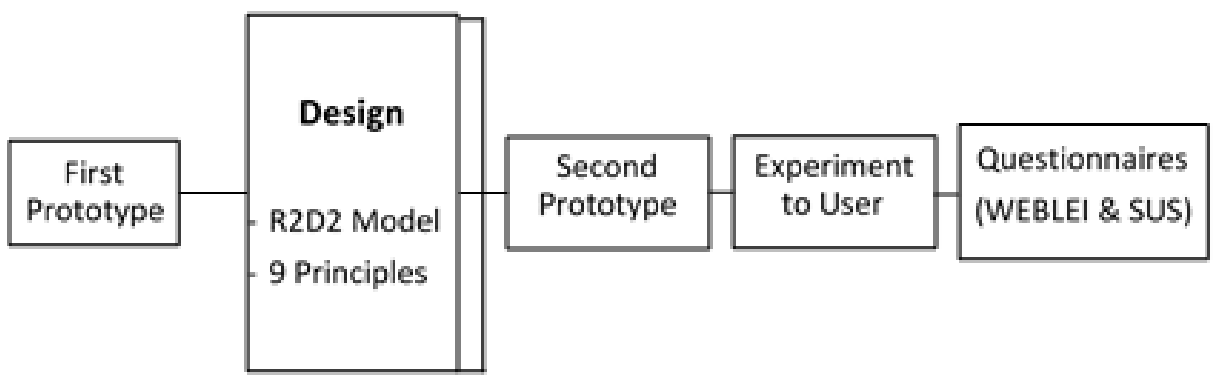

Figure 1. Research Framework 
The design process was started by re-design the first prototype into the second version. The design process adapted from Botturi et al. R2D2 process.

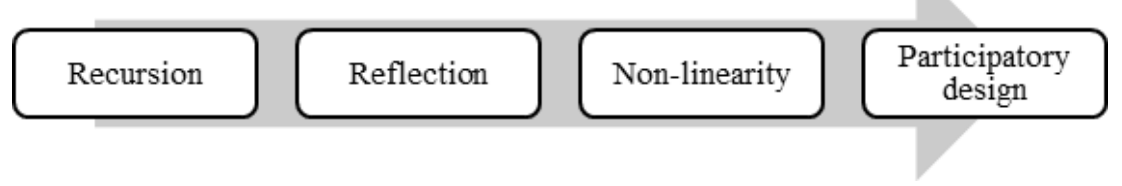

Figure 2. R2D2 Design Process adapted from Botturi et al

The first step on the design process is "Recursion", the purpose of this stage is to make a clear plan of the project in making the second prototype with the developer team by repeating the design thinking process until it become a clear concept. In this stage, the researcher, designer, and the programmer did several kinds of research about synchronous argumentation system, cognitive load theory, and knowledge building and also did research about User Interface and User Experience, after gaining knowledge about these matters, the team did a discussion to make a final decision on developing the second prototype. In this stage, the team also did revised ideas, plans, and concept. During the process of recursion, the team needs to analyze various aspects involving the users, tasks, and environment and then develop principles based on the researches by (Nielsen, 1994) and (Shneiderman et al., 2016). The output of this step is the nine design principles.

The second step is "Reflection", the purpose of this stage is to have a better vision and consideration of the process of developing the prototype and process further. Developer team did discussion again and consider some feedbacks and literature reviews that might help on the design process. The developer team working with their ideas and construct the decision based on the current situation while developing the prototype using the nine principles that the researcher develop earlier.

The third step is "Non-linearity", the purpose of this stage is to go further on the design process. Since it refers to prevent the lack of the previous stage before it reaches the next stage, in this stage, the team could refine and revise the plan through group interaction. The designer could elect to begin with any number of tasks through task analysis and make a decision which one should be revised.

The last step is "Participatory design", the purpose of this stage is to make a plan for the experiment subject, experiment activity and finish the final prototype. This stage refers to the involvement of the whole design team, which includes instructional designer, expert or researcher and the programmer on the subject matter as well as aspects of the instructional process or approach process, instruments and planning all the activities till it experimented on the user.

The experiment to user process was conducted by using 20 instruments of Web-Based Learning Environment (WEBLEI) adapted from Chang, V. (Chang, 2014), and ten instruments of The System Usability Test (SUS) adapted from Tullis and Stetson (Tullis \& Stetson, 2004). The Web-Based Learning Environment (WEBLEI) has four dimensions that would measure some aspects, the first aspect is "Emancipatory", which means free from restraint, control, or the power of another or free from bondage, the second aspect is "Co-Participatory" which means the act of participating with another or others, joint participation, the third aspect is "Qualia" which means a quality or property as perceived or experienced by a person, and the fourth aspect is "Information Structure \& Design", this aspect is related to the User Interface and User Experience.

The instruments divided into four dimensions. Four instruments to measure the emancipatory, eight instruments to measure the co-participatory, three instruments to measure the qualia, and five instruments to measure the information structure \& design. The System Usability Test (SUS) Instruments are the standardized instruments to measure the usability of the prototype with 10 instruments, which means 30 instruments in total. 
Table 1. Validity and Reliability Result of Adapted WEBLEI Instruments

\begin{tabular}{cccc}
\hline & & Validity and Reliability Test Result & \\
$\mathrm{N}$ & Items & Valid $(\%)$ & Cronbach's Alpha \\
48 & 20 & 100.0 & 0.917 \\
\hline
\end{tabular}

The result shows that the instruments that were tested to 48 students are valid. The reliability test used Cronbach's Alpha shows $91,7 \%$ for 20 items, according to Nunally Criteria (1960) if the Cronbach's Alpha $>60 \%$ means that the instruments are reliable, and it is above $90 \%$ means it is highly reliable.

The data collected after students tried both of the prototypes through questionnaires/instruments and interview questions to get more in-depth understanding of the user's learning experience using the prototypes.

For a better understanding of student's perception about the prototypes, the researcher interviewed three students from forty-eight students with three following questions:

- What do you think about the first and the second system interface?

- Will you use this kind of system in the future?

- What do you think makes the first and second system different? And which one do you prefer?

The interview result is included in the result and discussion, to help improve the system in the future through analyze student's perception on using the system.

The WEBLEI questionnaires analyzed with t-test were conducted to explore the difference between the result of the first prototype and second prototype, and SUS formula was conducted afterward to know the usability result between first prototype and second prototype. The interview result is presented to get a more in-depth understanding of their perceptions of the prototypes.

The Activities on $15^{\text {th }}$ April 2019 that conducted on $11^{\text {th }}$ grade class is to test the first prototype to the students. The activities are;

- Students watch the video about the first prototype. In this study, the researcher made an instructional video of the first system and how to use it. The purpose of this is to introduce the students to the system and make the students understand the system and how it works. This activity was successfully done.

- Students try the first prototype. The purpose of this activity is to make the students experience the argumentation activity with the system. This activity was successfully done.

- Students fill the first questionnaires. The purpose of this activity is to collect data and student's experience in using the system. This activity was successfully done.

The Activities on $18^{\text {th }}$ April 2019 that conducted on $11^{\text {th }}$ grade class is to test the second prototype to the students. The activities are;

- Students watch the video about the second prototype. In this study, the researcher made an instructional video of the first system and how to use it. The purpose of this is to introduce the students to the system and make the students understand the system and how it works. Unfortunately, because of the limited time, this activity was skipped. Also, students only remember about the previous video about the first version.

- Students try the second prototype. The purpose of this activity is to make the students experience the argumentation activity with the system and the difference between the first and the second system. This activity was successfully done.

- Students fill the first questionnaires. The purpose of this activity is to collect data and student's experience of using the second system. This activity was successfully done.

- The student interviewed about both of the prototypes. The purpose of this activity is to get a more in-depth understanding of student's perception of using both of the systems. This activity was successfully done. 


\section{Result}

\subsection{Implementation of Nine Design Principles}

The implementation of the principles can be shown on the numbers:

The first principle is shown in number one, that the screen design is aesthetically pleasing. Donald A. Norman in his book stated that attractive design is preffered over the untrattractive one (Norman, 2004). In this system, the main screen is divided into two main parts; there are comments part and argumentation map part. This design is arranged from left to right because based on the eye-tracking movement, people would read from left to right, it is based on human eyesight theory. The main color used for this prototype is dark purple and grey to decrease the cognitive load on students based on the theory that human eyesight for processing the important information on a colored screen would be better using less color, and it will reduce the eye fatigue.

The second principle is shown in number two, the arrangement of options/menus is appropriate. The options menus in this prototype include the hidden menus. This is to decrease the cognitive load on students because it is a synchronous system, students only need to see what menus that are considered more important to them, so they will not get distracted by too many options. According to Jitnupong, the system navigation is guidance that helps user in using the system. A satisfactory system should guide the user to the finish. The information that describes the details of the users' thinking processes comes from work-flow analysis, and navigation of the processes and reflected in the structure of the system in terms of layout such as template, the buttons position, content organization, system hierarchy, the tabs, menus, and also the border in the User Interface (Jitnupong \& Jirachiefpattana, 2018).

The third principle is shown in number three, the screen layout is easy to understand. The prototype is providing not only icons but also text, so students would be able to recognize and understand of each function. This principle could be seen on the prototype. There are two part of main screen function, the chat box and the argument map. The researcher used the student's knowledge and esperience in using web based chatting system, so this kind of layout is familiar with the student.

The fourth principle is shown in number four, flexible and efficient to use (for novice and expert user), in this prototype, the users could choose what type of users they are, so they will get different help to use this system. For a novice user, this system provide the guidance how to use the system and the function of each buttons. And for the expert user, since expert user already familiar with the functions, the expert user could skip this step and go ahead to use the system.

The fifth principle is shown in number five, provide help option for the user, the help function in this system is presented on the interface represented by the icon, on the right upper side of the interface.

The sixth principle is shown in number six, visibility of system status. Users should always know where they are and what is going on. In this system, the interface provides the argument history section, so when the student clicks on the comments, the student will know the history of their build on comments. The students will also know the real-time activity on the argument map.

The seventh principle is shown in number seven, consistency and standards. Use objects and phrases consistently. In this system, the icons, text, color, and shapes are consistent. This will decrease the extraneous cognitive load from students when they use the system because they will still be familiar with each of the functions.

The eighth principle is shown in number eight, error prevention and make user able to delete or undo. In this system, the undo function is replaced with the prompt text, because it will prevent them from commenting on something that is unrelated to the topic.

The ninth principle is shown in number nine, responsive. The way people access the Web is changing rapidly. The Web-based system is increasingly used in many devices. Therefore it is crucial the adoption of a new approach of creating Web-based system and making them able to adapt and respond to any device (Almeida \& Monteiro, 2017). This system is responsive on computer because every time someone posts a new comment, it will be 
shown in the comment section and argumentation map, but not in other devices. The responsive aspect is very important, especially because this system is a synchronous system.

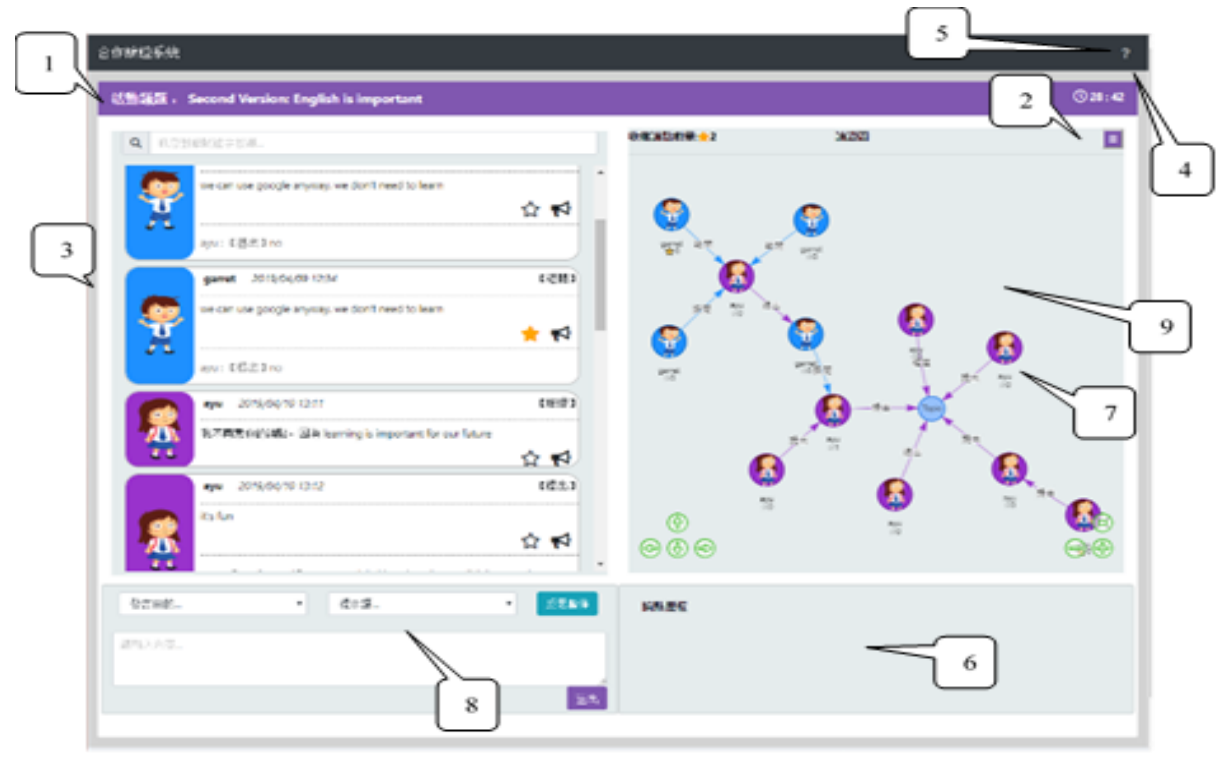

Figure 3. Synchronous Online Argumentation System's Interface

The meaning of a user interface is "A computer-mediated means to facilitate communication between human beings or between a human being and an artifact. The user interface embodies both physical and communicative aspects of input and output, or interactive activity" (Marcus, 2002). Then (Jitnupong \& Jirachiefpattana, 2018) concluded that the UI consists of metaphors, mental models, navigation, interaction and appearance that applied by the researcher and developer in this research into the nine principles for interface design.

"First impression of a user to the UI prototype will increase involvement, then ownership, and at last the satisfaction and also as a result, the team can receive feedback on the pros/cons of the system easier and faster than just by talking or writing something down" (Jitnupong \& Jirachiefpattana, 2018).

By using the nine principles into User Interface Design, helped to enhance the usability and appearance aspect of the system and increase the satisfaction in using the system. Using design principles would increase the effectivity of the system, according to (Brink et al., 2002) the importance of design principles in the web design, and specifically in the page design layout, even having as main reference the concept of usability. Costa et al also developed a literature review in order to identify some of the theory that principles in designing a web-based system is essential and it's important to use literature review to develop the design principles (Costa et al., 2004).

This design framework is designed to be effective to use on developing a system that will improve the User Interface design for a synchronous argumentation system to get better User Acceptance. "Designers should make every attempt to reduce the user's workload by taking advantage of the computer's capabilities. Users will make the best use of Web sites when information is displayed in a directly usable format and content organization is highly intuitive" (U.S Health and Human Service Guidelines, 2006). Research by Lestari et al proved that responsive web design was able to maintain the user experience quality of home functionality, content readability, and also reduce the amount of extensive action especially on scrolling (Lestari et al., 2014). In this design framework and nine design principles, the researcher and designer reduce the scrolling action and show the main interface and function to the user, so it would reduce the amount of extensive action. "To ensure the best possible outcome, designers should consider a full range of user-interface issues, and work to create a Web site that enables the best possible human performance" (U.S Health and Human Service Guidelines, 2006). 


\subsection{Result of WEBLEI and SUS Measurement}

Usability is crucial to any products, if the users can not achieve their goals effectively, efficiently, and in satisfactory manner, they can seek for alternative solutions to achieve their goals (Interaction-Design.Org).

The result from the WEBLEI questionnaire to measure four dimensions of the student's learning activity using the first and second prototype.

Table 2. WEBLEI Result with The First Prototype and Second Prototype

\begin{tabular}{llcc}
\hline \multicolumn{1}{c}{ Scale/Dimension } & $\begin{array}{c}\text { Prototype } \\
\text { (n=48) }\end{array}$ & Mean (S.D.) & t \\
\hline Emancipatory & Prototype 1 & $4.22(0.59)$ & 0.84 \\
Co-Participatory & Prototype 2 & $4.16(0.48)$ & \\
& Prototype 1 & $4.19(0.47)$ & $-2.10^{*}$ \\
Qualia & Prototype 2 & $4.29(0.43)$ & $-2.92^{* *}$ \\
Information Structure \& & Prototype 1 & $3.85(0.66)$ & \\
Design & Prototype 2 & $4.10(0.58)$ & $-3.46^{* *}$ \\
\hline
\end{tabular}

${ }^{*} p<0,05$

${ }^{* *} p<0.01$

The table proved that the Emancipatory dimension is $(\mathrm{t}=0.84)$ which means it has no significant difference, then the mean for the first prototype is $(M=4.22)$ and for the second prototype is $(M=4.16)$, which means that students feel the emancipatory aspect is slightly better on the first prototype than the second prototype. The Co-Participatory dimension is $(\mathrm{t}=$ -2.10) which means it has a significant difference, the mean for the first prototype is $(M=4.19)$ and for the second prototype is $(M=4.29)$, which means that students feel the Co-participatory aspect is better on the second prototype than the first prototype. The Qualia dimension is $(\mathrm{t}=$ -2.92) which means it has a significant difference, then the mean for the first prototype is $(M=$ $3.85)$ and for the second prototype is $(M=4.10)$ which means that students feel the qualia aspect is better on the second prototype than the first prototype. The Information Structure \& Design is $(t=-3.46)$ which means it has a significant difference, then the mean for the first prototype is $(M=4.10)$ and for the second prototype is $(M=4.30)$ which means that students feel the information structure \& design aspect is better on the second prototype than the first prototype.

This finding shows that the student's feel of emancipatory or freedom to explore the system or they are in control of using the system on the second prototype is lower than on the first prototype. This means that on the next development project, the researcher could fix this problem and improve the system to be better. The researcher can conduct a research about one of four aspects: Emancipatory, Co-Participatory, Qualia, and Information Structure \& Design for next prototype to get better undertanding of each aspect and deeper analysis.

To improve the method, researcher could use prototype theory approach to analyze websites based system to design online visual materials that will better meet different sets of human needs based on various aspects (St.Amant, 2009). To improve the emancipatory aspect, designer or developer could learn about children or teen aspect, because it cannot be denied that they share some common features that set children as a group apart from adults as a group. Some of these differences will eventually inevitably, transform into differences in the ability to interact with the world and digital artifacts in it (Jönsson, 2020). For more reference on children first attempt to understand the Child Computer Interaction (Read \& Bekker, 2011) did some analyses about involvement of adult participants in children's interactions, the contexts in which children use computer technology. 
The result from the SUS questionnaire to measure the usability of the first prototype and second prototype:

Table 3. SUS Result with The First Prototype and Second Prototype

\begin{tabular}{|c|c|c|c|}
\hline \multirow{2}{*}{$\begin{array}{l}\text { SUS Score } \\
(n=48)\end{array}$} & \multirow{2}{*}{$\begin{array}{c}\text { Average SUS Score } \\
\text { (odd items+even items) } \times 2.5\end{array}$} & Scale & \multirow{2}{*}{$\begin{array}{c}\text { Grading SUS Key } \\
\text { Best Imaginable }\end{array}$} \\
\hline & & \multirow{4}{*}{$\begin{array}{c}86-100 \\
74-85 \\
53-73 \\
39-52 \\
26-38 \\
1-25\end{array}$} & \\
\hline First Prototype & 64.27 & & \multirow{3}{*}{$\begin{array}{c}\text { Excellent } \\
\text { Good } \\
\text { OK } \\
\text { Poor } \\
\text { Worst Imaqinable }\end{array}$} \\
\hline Second Prototype & 68.90 & & \\
\hline \multicolumn{2}{|c|}{ Difference: 4.43 (higher on the second prototype) } & & \\
\hline
\end{tabular}

Based on System Usability Scale (SUS) result, proved that the average score for the first version is (A.SUS=62.27) which means the prototype grade is "Good", and the average score for the second version is (A.SUS= 68.90) which means the prototype grade is also "Good", but there is 4.43 average difference score from first to the second prototype. Which means that the second prototype has 4.43 higher score from the first prototype, and that means the second prototype is better than the first prototype.

Table 4. Interview with The First Prototype and Second Prototype

\begin{tabular}{|c|c|c|c|}
\hline Question & Student A & Student B & Student C \\
\hline $\begin{array}{l}\text { What do you think } \\
\text { about the first and the } \\
\text { second system } \\
\text { interface? }\end{array}$ & $\begin{array}{l}\text { "I think the first system is } \\
\text { easy to understand, and the } \\
\text { second system is also easy } \\
\text { to understand. However, } \\
\text { on the first system, I have } \\
\text { to keep scrolling on the } \\
\text { argument map to be able to } \\
\text { read the comments." }\end{array}$ & $\begin{array}{l}\text { "It is better now (the } \\
\text { second version). It has } \\
\text { variation in the icons, } \\
\text { and it makes it easier to } \\
\text { do the argumentation." }\end{array}$ & $\begin{array}{l}\text { "Both are easy to use, but the } \\
\text { second version provides more } \\
\text { help. The first version is like } \\
\text { the old type, and the second } \\
\text { version is like the new one." }\end{array}$ \\
\hline $\begin{array}{l}\text { Will you use this kind } \\
\text { of system in the } \\
\text { future? }\end{array}$ & "I think I will use it." & "Maybe sometimes." & "I think so." \\
\hline $\begin{array}{l}\text { What do you think } \\
\text { makes the first and } \\
\text { second system } \\
\text { different? And which } \\
\text { one do you prefer? }\end{array}$ & $\begin{array}{l}\text { "The colors, the interface, } \\
\text { and the argumentation } \\
\text { map. I think I like the } \\
\text { second version better since } \\
\text { I like the color and it is } \\
\text { cute." }\end{array}$ & $\begin{array}{l}\text { "The colors? And it has } \\
\text { more function like there } \\
\text { are } 30 \text { seconds delayed } \\
\text { time, at first I do not } \\
\text { know how to use that. I } \\
\text { think I like the second } \\
\text { version." }\end{array}$ & $\begin{array}{l}\text { "The delayed function? I do } \\
\text { not know why we have to be } \\
\text { delayed for commenting, and } \\
\text { I think it would be better if } \\
\text { we can chat with more } \\
\text { people. And also it would be } \\
\text { easier if the enter just like on } \\
\text { Facebook like we just have to } \\
\text { press enter to comment." }\end{array}$ \\
\hline
\end{tabular}

Based on the interview result, we found that students were agreed that both of the prototypes are easy to use. The improvement from the first to the second prototype is the students likes the interface and experience on the second prototype more than on the first prototype. The students were agreed that the prototype is worth to use, and they will use this kind of system in the future. Moreover, the researcher also found out that it is better to introduce the students to the prototype not only by introducing them to the functions but also the purpose of each function or reflection and pause, for example not all students will understand the function of the delayed comment function. Related research about adaptable and adaptive User Interface on conference paper about Design Adaptable and Adaptive User Interface: A Method to Manage the Information, that aimed to produce goods able to automatically satisfy the different skills, abilities also needs and human preferences, and not simply finding a single solution for everyone (Gullà et al., 2014). 


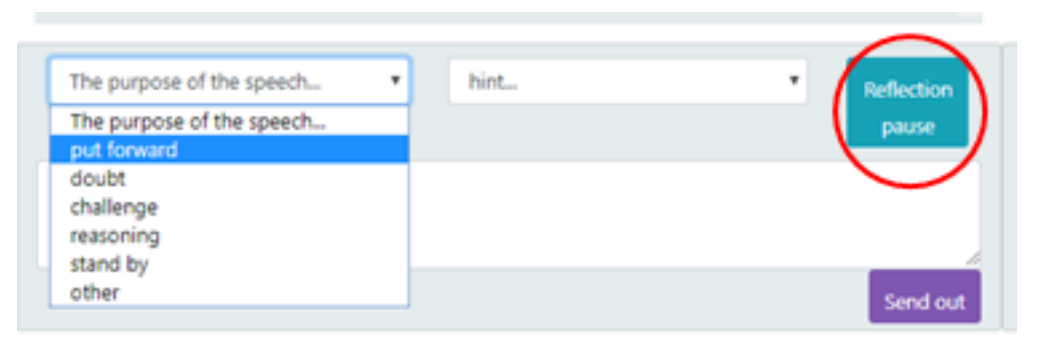

Figure 4. Synchronous Online Argumentation System's Reflection/Pause Function

The introduction of the prototype could include a brief introduction about argument map, the purpose and how to use it, so the students could use the prototype better and will have a more definite purpose and goals on using it. It is best to not skip the scenario plan, for example, the introduction video, in this research the introduction video for the second system was skipped, so the student needs more time to figure out about each new function that different from the first system. Other related research that could be a reference for human-centered design is by Sharon Oviatt that explain about Human-Centered Design Meets Cognitive Load Theory: Designing Interfaces that Help People Think, that would give better understanding of how humans think and how to design the interface based on that (Oviatt, 2006).

The nine principles are not only able to be applied on a synchronous system, but also asynchronous system but this also should be tested with a new research in the future. The principles also consider the factors of interest are accuracy and efficiency by providing the expert and novice function, because it is important for novice users to quickly learn the system and the developer design the system to precisely supply the input. Based on the research result, we found that the nine principles could be implemented and improve the User Experience through well-designed User Interface.

\section{Discussion}

The purpose of developing a system or technology is to help human being to accomplish their goals and fulfill their needs. And despite the advances in assistive technologies to improve the usability and accessibility of User Interfaces on a system, there is still a gap in how to handle the differences among each user with different needs (Machado et al., 2018). In this research, the user is defined by the expert user and novice user, which mean they have different needs, and this system provided the function for these types of user, and was designed for high school students. The design of a system would be different depends on the purpose of developing a system and user needs. With the use of e-learning tools such as the developed systems exist today, the human mind could process a large amount of information that exceeds its capacity which would reduce the learner's ability to gain the necessary knowledge from the tool and add it to existing knowledge so it can to be used in new situations (Mayer \& Moreno, 2003). So, it's important to provide the right solutions and decrease the cognitive load that the user might encounter while using the system. It is also important to consider the traditional learning environment when the information is exchanged from the instructor to the learner in a face-to-face setting, in this environment concepts can be built up over time so that the learners cognitive load can be managed and they can achieve the greatest possible learning outcomes (Asraj et al., 2011).

For further research, it would be better to also consider about user's background more, for example, user's age, user's educational background, user's nationality and other aspects, so the researchers could gain more information and result to the variety of users. To gain deeper understanding of exploring significant differences in how people from diverse cultural backgrounds and diverse individual characteristics perceive and use web-based system, Zahedi et al done a research based on this matter and provide the conceptual model to assist us working with various web designs (Zahedi et al., 2001).

"The main concern for instructional designers is to develop the most appropriate method for an organizations or present the information to its learners in the best possible manner, 
which involves taking into consideration a number of factors (Asraj et al., 2011)." We have to examine this framework and nine design principle again by conduct more research using this framework again with different method to gain more information and result, so we can keep developing effective and efficient design framework.

It's also important to test the efficiency aspect that hasn't been tested yet in this research. There are many researches done experiments to measure cognitive load aspect but "In general, there has been limited success in disentangling and measuring different types of cognitive load and current research in this area features considerable discrepancies in the wording of cognitive load measures, when they are collected during an intervention and how efficiency is defined and used (Martin, 2015).

\section{Conclusions}

This research emphasized the research conclusion by Chen "Synchronous leaming is becoming more and more important with the improvements in technologies such as broadband Intemet access" (Chen et al., 2005). This research proved that the nine principles are good, applicable, and qualified to be used in designing a system to achieve better usability aspect to design a better system in the future. For the future research, it would be a research to study about the Cognitive Load field on students, measure their Cognitive Load and test if the future system really works on decrease the Cognitive Load and what strategy and method that would be helpful for the next research. For the future research would be better to do the Cognitive Load research first before applying the design principles to make a system because every student in different school or country might have different result and needs.

Based on the findings in this study, it would be better to have more time to introduce a new function to the students before letting them use the system. Because some students need a better understanding of this function. To apply the nine principles to develop a system is best by really do the User Experience research first to understand the user needs. This system is responsive on computer because every time someone posts a new comment, it will be shown in the comment section and argumentation map, but not in other devices yet. In the future research, the designer could develop a system that responsive in any devices.

These principles must be interpreted, refined, and extended for each environment. They have their limitations but will provide a good starting point for mobile, desktop, and web designers. The principles presented in the ensuing sections focus on increasing the usability of the system.

\section{References}

Almeida, F., \& Monteiro, J. (2017). The role of responsive design in web development. Webology, 14(2), 48-65.

Asraj, A. Al, Freeman, M., \& Chandler, P. A. (2011). Considering cognitive load theory within e-learning environments. PACIS 2011 - 15th Pacific Asia Conference on Information Systems: Quality Research in Pacific, 1-13. https://ro.uow.edu.au/cgi/viewcontent.cgi?article=2288\&context=infopapers

Botturi, L., Lepori, B., \& Tardini, S. (2006). Fast Prototyping as a Communication Catalyst for E-learning Design. Making the Transition to E-Learning: Strategies and Issues, January, 266-283. https://doi.org/10.4018/978-1-59140-950-2.ch016

Brink, T., Gergle, D., \& Wood, S. D. (2002). Usability for the Web DesignWeb sites That Work. Morgan Kaufmann Publishers.

Chang, V. (2014). The Web based Learning Environment Instrument ( WEBLEI ). 1996, 6-11.

Chen, N. S., Ko, H. C., Kinshuk, \& Lin, T. (2005). A model for synchronous learning using the Internet. Innovations in Education and Teaching International, 42(2), 181-194. https://doi.org/10.1080/14703290500062599

Costa, C. J., Costa, P., \& Aparício, M. (2004). Principles for creating web sites: A design perspective. Principles for Creating Web Sites: A Design Perspective, January, 484-488.

Gullà, F., Ceccacci, S., Germani, M., \& Cavalier, L. (2014). Design Adaptable and Adaptive User Interfaces: A Method to Manage the Information. Research Trends in Media Informatics, 426(April), 39-46. https://doi.org/10.1007/978-3-319-18374-9 
Hotcomm. (2003). Synchronous Tools and the Emerging Online Leaming Model. 1-4. http://hotcomm.com/tec/dlwp.pdf

Hrastinski, S. (2007). Participating in Synchronous Online Education. In Management. School of Economics and Management, Lund University. KFS AB. http://lup.lub.lu.se/luur/download?func=downloadFile\&amp;recordOld=599311\&amp;fil eOld $=600490$

Jitnupong, B., \& Jirachiefpattana, W. (2018). Information System User Interface Design in Software Services Organization: A Small-Clan Case Study. MATEC Web of Conferences, 164. https://doi.org/10.1051/matecconf/201816401006

Jönsson, D. H. (2020). The emancipatory potential of child-computer interaction (Issue February 2019, pp. 1-13). https://uxdesign.cc/the-emancipatory-potential-of-childcomputer-interaction-e84f7a95a3d0?gi=ebddd1826fd

Leidner, D. E., \& Jarvenpaa, S. L. (1995). The Use of Information Technology to Enhance Management School Education: A Theoretical View. Journal - Association of Official Analytical Chemists, 71(3), 557-559. https://doi.org/10.1093/jaoac/71.3.557

Lestari, D. M., Hardianto, D., \& Hidayanto, A. N. (2014). Analysis of user experience quality on responsive web design from its informative perspective. International Journal of Software

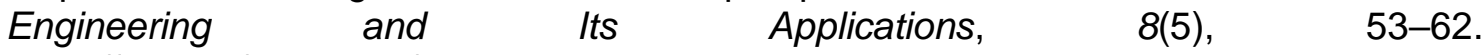
https://doi.org/10.14257/ijseia.2014.8.5.06

Machado, E., Singh, D., Cruciani, F., \& Chen, L. (2018). A Conceptual framework for Adaptive User Interfaces for older adults. A Conceptual Framework for Adaptive User Interfaces for Older Adults: IEEE International Conference on Pervasive Computing and Communications Workshops, PerCom Workshops 2018, October, 782-787. https://doi.org/10.1109/PERCOMW.2018.8480407

Marcus, A. (2002). Dare we define user-interface design? Interactions, 9(5), 19-24. https://doi.org/10.1145/566981.566992

Martin, S. (2015). Measuring cognitive load and cognition : metrics for technology enhanced learning. Educational Research and Evaluation.

Mayer, R. E., \& Moreno, R. (2003). Field investigation of the performance of soft soil reinforcement with inclined pile. Nine Ways to Reduce Cognitive Load in Multimedia Learning, $\quad$ 2(1), 43-52. https://faculty.washington.edu/farkas/WDFR/MayerMoreno9WaysToReduceCognitiveL oad.pdf

Nielsen, J. (1994). Human Factors Computing Systems: Enhancing the Explanatory Power of Usability Heuristics. Human Factors in Computing Systems, 152-158.

Nielsen, J. (2012). Usability 101: introduction to usability [Online] (pp. 3-5). https://www.nngroup.com/articles/usability-101-introduction-to-usability/

Norman, D. A. (2004). Emotional Design: Why We Love (Or Hate) Everyday Things. In Residential Treatment for Children and Youth (Vol. 13, Issue 2). https://doi.org/10.1300/J007v13n02_06

Oviatt, S. (2006). Human-Centered Design Meets Cognitive Load Theory: Designing Interfaces that Help People Think. Proceedings of the 14th Annual ACM International Conference on Multimedia, MM 2006, 871-880. https://doi.org/10.1145/1180639.1180831

Read, J. C., \& Bekker, M. M. (2011). The nature of Child Computer Interaction. The Nature of Child Computer Interaction Janet, 1994, 1-9. https://doi.org/10.14236/ewic/hci2011.43

Shneiderman, B., Plaisant, C., Cohen, M., Jacobs, S., \& Elmqvist, N. (2016). Designing the User Interface: Strategies for Effective Human-Computer Interaction: Sixth Edition (pp. 5-6). Pearson (May 2016). https://xd-i.com/blog/ben-shneiderman-the-eight-goldenrules-of-interface-design/

Sodiya, A. S. (2016). User Interface Design, And Ergonomics. The National Open University of Nigeria.

St.Amant, K. (2009). Technical Communication Quarterly Explicit Structure in Print and OnScreen Documents. A Prototype Theory Approach to International Website Analysis and Design, 14(1), 9-30. https://doi.org/10.1207/s15427625tcq1401 
Tullis, T. S., \& Stetson, J. N. (2004). A Comparison of Questionnaires for Assessing Website Usability ABSTRACT : Introduction. Usability Professional Association Conference, June 2006, 1-12. http://home.comcast.net/ tomtullis/publications/UPA2004TullisStetson.pdf

U.S Health and Human Service Guidelines. (2006). Research-based web design \& usability guidelines (Vol. 2009, Issue July 12). The U.S. Department of Health and Human Services 200 Independence Avenue, S.W. http://www.usability.gov/pdfs/guidelines.html

Willis, J. (2009). A General Set of Procedures for C-ID: R2D2. In J. Willis (Ed.), Constructivist Instructional Design (C-ID): Foundations, Models, and Examples. Charlotte, NC: Information Age Publishing.

Zahedi, F. M., Van Pelt, W. V., \& Song, J. (2001). A conceptual framework for international Web design. IEEE Transactions on Professional Communication, 44(2), 83-103. https://doi.org/10.1109/47.925509 